\title{
A FILOSOFIA E A HISTÓRIA DA CIÊNCIA COMO ESTRATÉGIA PARA RESSIGNIFICAR O ENSINO NO CURRÍCULO INTEGRADO
}

\author{
Ricardo Antonio Rodrigues ${ }^{1}$ \\ Fernanda Lavarda Ramos de Souza² \\ Liára Colpo Ribeiro ${ }^{3}$
}

\section{RESUMO}

O Currículo Integrado exige uma abordagem interdisciplinar dos conceitos e conteúdos por parte dos docentes, tendo em vista a necessidade de que sejam constituídos pontes e diálogos entre os diferentes saberes, seja pelas disciplinas básicas ou técnicas. A abordagem de conceitos mais dedutivos formais em sala de aula pode produzir no estudante desencantamento se a ciência, a técnica e a tecnologia não forem humanizadas. A História e a Filosofia da Ciência podem ser o caminho mais eficiente para oportunizar uma experiência mais próxima da realidade do discente. Humanizar-se e humanizar a ciência e a tecnologia são meios eficazes para incluir no ato educativo, junto com os conteúdos e conceitos a serem trabalhados, a possibilidade de que o aluno se faça as perguntas originárias, filosóficas e científicas que foram feitas através da história e se sinta convocado para ser produtor de conhecimento, não apenas um espectador de aulas sobre ciência e tecnologia. Nada pode ser mais eficaz do que o discente se sentir motivado a pensar de modo filosófico e científico o mundo da ciência e da tecnologia à luz da interdisciplinaridade, algo inerente ao Currículo Integrado.

Palavras-chave: Ciência. História da Ciência. Filosofia da Ciência. Currículo integrado.

\section{PHILOSOPHY AND THE HISTORY OF SCIENCE AS A STRATEGY TO RETHINK TEACHING IN THE INTEGRATED-CURRICULUM}

\begin{abstract}
The Integrated-Curriculum requires an interdisciplinary approach to the concepts and contents by the teachers, given the need for bridges and dialogues to be established between the different types of knowledge, whether through fundamental or technical disciplines. The approach of more formal deductive concepts in the classroom can produce disenchantment in the student if science, technique, and technology are not humanized. History and Philosophy of Science can be the most efficient way to create an experience closer to the student's reality. Humanize ourselves and humanizing science and technology are effective ways to include in the educational activities, along with the contents and concepts to be worked on, the possibility for the student to ask the original, philosophical and scientific questions that have been asked through history and feel called to be a knowledge producer, not just a spectator of science and technology classes. Nothing can be more effective than students feeling motivated to think philosophically and scientifically about the world of science and technology in the light of interdisciplinarity, something inherent to the Integrated-Curriculum.
\end{abstract}

Keywords: Science. History of Science. Philosophy of Science. Integrated-curriculum.

Recebido em: 5/5/2020

Aceito em: 30/6/2020

\footnotetext{
1 Licenciatura em Filosofia (habilitação Sociologia e Psicologia). Especialização em Metodologia do Ensino. Mestrado em Ética e Filosofia Social. Doutorado em Filosofia, Epistemologia e Metafísica. Pós-Doutorado em Ética e Filosofia Política. Docente de Filosofia do Iffar, Campus Jaguari/RS. Docente do quadro permanente do Programa de Mestrado Profissional em Educação Profissional e Tecnológica e coordenador do curso de Mestrado ProfEPT. http://lattes.cnpq.br/2052548816755075. https://orcid.org/0000-0002-5292-3646. rianro@gmail.com

2 Odontóloga (TAE - Iffar Campus Jaguari/RS). Mestranda em Educação Profissional e Tecnológica no Programa de Mestrado em Educação Profissional e Tecnológica. http://lattes.cnpq.br/8960254161861638. https://orcid.org/0000-0002-8761-6929. fernanda.souza@iffarroupilha.edu.br

3 Licenciatura em Ciências Biológicas. Mestrado em Ensino de Ciências. Docente EBTT de Biologia. Coordenadora do Curso Técnico Integrado em Sistemas de Energia Renovável (Iffar, Campus Jaguari/RS). http://lattes.cnpq.br/1231144364984080. http://orcid.org/0000-00024445-3314. liara.ribeiro@iffarroupilha.edu.br
} 
Um dos discursos recorrentes em nosso tempo é o desinteresse dos estudantes pelas aulas e pela produção do conhecimento. Notadamente, parece que as aulas não despertam a curiosidade mínima para que busquem saber mais em cada área específica do conhecimento. Há, não muito difícil de ser comprovado, certo tédio pelo modo como conduzimos nossos encontros e uma dificuldade bastante grande de despertarmos o interesse pelo saber científico, tecnológico e mesmo filosófico.

Não é adequado ancorarmos nossas mazelas do processo complexo de ensino e aprendizagem em culpabilizar os docentes ou, de outro modo, os discentes. Esta proposição textual não pretende levianamente acusar uma ou outra categoria, quer dos docentes, quer dos discentes. Nem mesmo defender que a tecnologia ou qualquer outra estratégia possa ser a única forma ou maneira de solucionarmos os desafios do ensino. Sempre serão inúmeras causas e inúmeras soluções, conforme o contexto em que estivermos inseridos.

Para pensarmos essa problemática no Currículo Integrado, temos de considerar o que dispõem Frigotto, Ciavatta e Ramos (2005) sobre o que é um Currículo Integrado e também o que sugerem Fazenda (1999) e Santomé (1998) sobre o que significa e implica a interdisciplinaridade. A interdisciplinaridade é a condição para que uma cabeça seja benfeita (MORIN, 2004b), também considerando que ensinar é religar e conectar saberes (MORIN, 2004a) e produzir a possibilidade do conhecimento do conhecimento (MORIN, 2014), a sabedoria. Uma sala de aula não pode ser uma assembleia da ONU, em que cada sujeito apenas se ocupa de sua demanda (MORIN, 1990, 2004a), mas um espaço privilegiado de religação dos saberes (MORIN, 2004a), conexão de sentido entre o que está sendo aprendido e a significância disso na vida prática e cidadã do aprendiz (NUSSBAUM, 2010)

O que este texto pretende analisar é a importância de nos valermos no Ensino Básico da História e da Filosofia da Ciência como estratégia para ressignificar nossas aulas, para despertar a curiosidade mínima, apresentando o contexto e os pretextos que levaram à produção de cada conhecimento, considerando a ciência como construção e produção humana contínua. Nesse contexto, a ideia é estimular o discente a se sentir em dois momentos específicos da História: a) no contexto e pretextos da origem daquele conhecimento específico, com erros e acertos que fazem parte de qualquer produção de conhecimento; b) que o estudante possa atualizar a problemática daquele conhecimento em seu tempo, compreendendo-se como possibilidade de, a partir do entendimento de como se originou aquele conhecimento, poder aperfeiçoá-lo e sentir-se com a curiosidade e interesse mínimo para ser também um produtor de conhecimento e tecnologia, não apenas um consumidor passivo de informações e conhecimento.

A função do ensino não é enfadonhamente reproduzir saberes sem contextos e pretextos, jogar para as novas gerações o que as anteriores produziram, impondo respostas para quem ainda não fez as devidas perguntas, mas buscar todas as formas e modos para produzir novos cientistas, novos pensadores e sujeitos autônomos diante do saber e do fazer humanos, recriando, inovando e reconstruindo o conhecimento como algo vivo e em constante processo de transformação. 
A contribuição da História da Ciência é diferente da Filosofia da Ciência, não significa com isso que se esteja fazendo um juízo de valor a respeito. Pelo contrário, embora se tenha mais produção e um certo espaço reservado até mesmo nos currículos de Licenciaturas para a disciplina de Filosofia da Ciência, defendemos que ambas são fundamentais para facilitar o ensino, apresentando ao discente o cenário, o contexto, a pergunta originária, o problema, os erros, as tentativas e o objetivo central de como e por quê se produziu aquele tipo de conhecimento. $O$ que está sendo defendido aqui é que há uma indissociabilidade da Filosofia e da História da Ciência para o ensino em todo e qualquer tipo de conhecimento, tanto por questões epistemológicas, pedagógicas, metodológicas, mas principalmente por questões de alfabetização científica e tecnológica. Para que o discente não apenas seja um leitor passivo da ciência e da tecnologia, mas um ator, um sujeito responsável e corresponsável para a manutenção e perpetuação de novos saberes e fazeres.

Fala-se tanto em autonomia e empoderamento pelo conhecimento, e o sentido do ensino é justamente isso. Notamos nos textos originários da Filosofia grega que o objetivo do ensino, da educação, para Platão (1999) no livro As Leis e, para Aristóteles (1990), na Ética a Nicômacos, é justamente a enkrateia (autodeterminação, bom governo de si). Tanto na Academia de Platão como no Liceu de Aristóteles, o ensino visava junto com a difusão do conhecimento a produzir a autodeterminação dos aprendizes. A História e a Filosofia da Ciência têm esse papel insubstituível de reelaborar o sentido e a forma do ensino, considerando sua função prioritária e originária. Ensinar não é transmitir respostas prontas para quem ainda não fez adequadamente as referidas perguntas. Ensinar é prioritariamente remontar as perguntas originais para que possamos dar as respostas adequadas em nosso tempo. Sem a pergunta ressuscitada, oxigenada, renovada e atualizada, é provável não haja interesse por aquele tipo ou modo de conhecimento.

Aristóteles (1969) no começo da Metafísica, livro 1, traz duas questões fundamentais para a formação do espírito científico em sala de aula. No início do livro 1 ele destaca que todo ser humano carrega em si o desejo de conhecer. Que a nossa característica mais marcante como seres racionais é penetrar o mistério e extrair elementos que possam amparar nossa existência, compreender e explicar o mundo, entender e prever fenômenos. Enfim, literalmente nos permitir sair da caverna do conhecimento aparente (agnósis) para chegarmos ao terceiro nível, como afirmou Platão, ${ }^{4}$ que é a Epistemé (conhecimento mais elaborado, ver além do que se vê, conhecimento intelectual). Em nossos processos de ensino precisamos sempre partir da premissa de que o seu sentido último não é a difusão do conhecimento em si, mas o empoderamento dos discentes pelo acesso e compreensão do conhecimento para com ele e, através dele, transformar-se e transformar o mundo, ou, pelo menos, a realidade em que está inserido.

\footnotetext{
4 Para Platão, em seu triângulo ou pirâmide do conhecimento, a base inferior seria a ignorância ou conhecimento aparente, quando o indivíduo preso na caverna não distingue o que é o ser e o que é a sombra (agnósis). Numa proposição mais elaborada, quando o sujeito se afasta minimamente da ignorância ele se eleva para ter a opinião (doxa), que em seu entendimento ainda não é conhecimento. No modo mais elevado, na parte superior da pirâmide ou triângulo está a Epistemé, ou um conhecimento mais elaborado, mais refletido, crenças justificadas pela realidade e pela reflexão, em si, o conhecimento intelectual, aquele que filosoficamente permite ver para além do que se vê: idein, ideia em grego, significa, ver intelectualmente.
} 
Desse modo, a História e a Filosofia da Ciência irão mexer em questões importantes nas bases do que ensinamos, começando pela contextualização originária da pergunta essencial que gerou aquele conhecimento, as motivações, necessidades e desafios que pretendiam ser resolvidos conectando isso ao discente, para que possa a partir da ressurreição e ressignificado da pergunta originária imbuir-se de novas perguntas e, em consequência, propor as suas questões e buscar novas respostas a partir da compreensão da resposta originária in loco (intelectualmente falando) dada.

A proposição aqui não é ensinar História e Filosofia da Ciência em suas aulas, nos mais diferentes componentes curriculares, mas que essa apropriação pelos docentes dessas disciplinas favoreça e potencialize aulas que oportunizem aos discentes merguIhar no mistério da pergunta originária que gerou aquele determinado saber e, com isso, estimular o estudante a refletir e assumir-se como sujeito, no sentido de compreender, revisar e até mesmo aprimorar a pergunta originária, reacendendo seu papel como autor e produtor de seu próprio itinerário formativo, visando a restabelecer o pasmo essencial e inicial em torno de tal tema, descendo à toca do coelho, numa acepção à Alice no País das Maravilhas. ${ }^{5}$ Como defendia Einstein (1981), não há possibilidade de constituirmos efetivo conhecimento, em qualquer área, sem considerarmos o ponto de partida comum, que é mergulhar no mistério.

\section{A CIÊNCIA COMO PRODUTO HUMANO - O PAPEL INSUBSTITUÍVEL DA FILOSOFIA DA CIÊNCIA NA FORMAÇÃO DOS PROFESSORES}

Faz toda diferença teórica e prática, em nossas práxis, compreendermos a ciência como fabricação humana (CHALMERS, 1994). Isso porque há, a priori, a desmistificação de que ciência é uma coisa ou atividade para pessoas notada ou dotadamente especiais. Se a ciência é construção humana, como premissa podemos inferir que, em tese, todo e qualquer ser humano também pode fazê-la, ressignificá-la e (re) construí-la. Não se trata de desconsideração à ciência, de sua banalização ou sujeição ao conhecimento empírico e ao senso comum. O que se está propondo aqui é que o foco de nossos discentes seja a alfabetização científica, na mesma perspectiva de Bachelard $(1996,2006)$, um esforço para que possamos minimamente, formar o espírito científico de nossos discentes e não apenas repassarmos informações desconexas, sem a visita à pergunta fundamental que derivou aquele conhecimento.

No entendimento de Kuhn (1978), a ciência é falível. Esse falibilismo não a invalida e não a desqualifica enquanto tal. Na sua noção da ciência como quebra-cabeça, ciência normal, há ressignificação da ciência como algo pronto e acabado para um processo vivo em constante construção. Para este autor (1978), a crise da ciência ou de uma teoria específica da/na ciência tanto pode ser produzida por elemento externo, uma descoberta ou crise gerada por uma nova descoberta, ou mesmo por algo produzido e descoberto dentro da própria ciência. O exemplo mais evidente é a teoria do geocentrismo de

\footnotetext{
Na clássica obra de Lewis Carroll (2009), Alice no País das Maravilhas, a menção à toca do coelho, em nossa interpretação, tem relação com a ideia do desconhecido, o inesperado, aquilo que desafia e aguça a curiosidade humana em direção ao mistério. Refazendo o adágio socrático, é o desejo de conhecer o primeiro passo para a sabedoria. Descer à toca do coelho é, portanto, fazer a experiência curiosa do mistério.
} 
Ptolomeu, assumida por Aristóteles, a qual perdurou por muito tempo na humanidade até ser superada pela teoria do heliocentrismo e problematizada mais tarde por teorias que defendem a infinitude do universo, para a qual a disposição elíptica não cabe. Um exemplo disso é a proposta de Giordano Bruno, no final do século 16, de que sendo o universo infinito, propor que o Sol ou a Terra sejam o centro não faz muito sentido. Sua tese, entre outros aspectos, buscava dizer que tanto Aristóteles como seus críticos (Galileu e Copérnico) estavam errados ao defenderem modelos elípticos (geocentrismo ou heliocentrismo).

Assim como o geocentrismo foi substituído pelo heliocentrismo, muitas teorias e leis foram, historicamente, sendo melhoradas, complementadas, redirecionadas e mesmo abandonadas em decorrência de uma crise provocada internamente ou externamente, como postulou Kuhn (1978). A crise de um sistema, de um modelo, revela, antes de tudo, que nenhuma proposição racional é absoluta o tempo todo ou em todos os tempos. Essa compreensão de que há um falibilismo na ciência abre uma possibilidade grande de que os próprios docentes e discentes sejam convidados a serem construtores e produtores de ciência, de saberes e fazeres que, embora provisórios, numa perspectiva teórica de Kuhn, são de fundamental importância para mantermos a produção do conhecimento e da ciência de modo operante, ativo e autoral. Compreender a falibilidade da ciência é convocação para o seu aperfeiçoamento, para sua consolidação e o convite para fazermos o mícron que cabe a cada um. A ciência é processo vivo, e, assim deve ser apresentada, problematizada e vivenciada com as novas gerações.

O estabelecimento de paradigmas como modelos provisórios, tendo presente as bases sobre as quais se assentam tais modelos, permite uma relação mais oxigenada e aberta dos docentes de cada componente, permitindo que a aula seja, antes de tudo, a apresentação benfeita de como a pergunta originária se constituiu e não sejam de modo enfadonho e entediante apresentadas as respostas e soluções descontextualizadas. Essa perspectiva histórica e epistemológica de pensarmos a ciência e seu ensino dentro de certos paradigmas permite-nos uma visão muito mais acurada e crítica de nosso trabalho docente.

Para Boaventura de Sousa Santos (2010), na obra Um Discurso Sobre as Ciências, é de suma importância que na condição de produtores de ciência, saibamos em qual paradigma estamos produzindo ou propondo a produção de saberes. Em sua proposta, há o paradigma dominante, marcadamente cartesiano e positivista, contraposto pela necessidade de um paradigma emergente, mais atual, e que dê conta dos desafios de nosso tempo de modo mais crítico, holístico e com uma compreensão da realidade que seja mais rica de sentido e significado. Na verdade, sempre ensinamos de um lugar, de um aporte teórico, de uma base epistêmica específica, quer tenhamos clareza disso ou não.

Para Popper (1968) o campo da ciência está posto no que poderíamos afirmar como neopositivismo lógico. Mantém-se a proposta de Augusto Comte, que não devemos partir de uma certeza, mas de uma hipótese que precisa ser testada. O método hipotético-dedutivo não é criação de Popper, é adaptação da concepção positivista de método. Para compreendermos melhor precisamos comparar a posição de Popper com as correntes filosóficas do empirismo e do racionalismo. 
No empirismo inglês temos o externalismo epistêmico, porque a base para a validação do conhecimento é a experiência e não a razão. E, também, é a realidade externa que imprime sentido e significado aos sentidos que apreendem a verdade. De modo diverso, portanto, do realismo que atribui aos sentidos um papel de mediação entre o intelecto e a coisa. Para o empirismo (empiria, em grego, experiência) a realidade impõe à mente sua potencialidade de estabelecimento da verdade, por isso, chamamos, também, de externalismo. A confirmação última da verdade, do ponto de vista epistêmico, está na realidade externa ao ser humano.

No racionalismo francês, de modo diverso, é a razão humana que atribui último assentimento da verdade científica. Por isso denominamos, também, o racionalismo, em epistemologia, de internalismo. Nessa perspectiva, os sentidos ocupam um papel menos importante na produção do conhecimento. Na acepção de Descartes (1996), no célebre Discurso do Método, os sentidos não podem ser tomados por referência tanto para produzir o conhecimento como para validá-lo, porque eles podem enganar. O cogito cartesiano possui a certeza de que não podemos cair no ceticismo, mas também propõe certa suspeição na importância dos sentidos na produção do conhecimento.

Para Popper (1968), o método racionalista pode incorrer no mesmo problema já apresentado por Platão, em que um dedutivismo intelectivo é incapaz de dar conta de determinados contextos da realidade. Para Popper (1968), o dedutivismo inibe a intuição e esta é fundamental para a produção do conhecimento, tanto que certas conquistas e descobertas em ciência não foram deduzidas de teorias abstratas, como no caso de Albert Einstein e de Isaac Newton. A observação e a reflexão sobre essas questões podem derivar intuições que são, de modo geral, tão importantes quanto as comprovações nas mais diferentes áreas. A intuição é uma aliada da descoberta científica, não à toa que alguns autores dedicaram parte de sua obra para a heurística.

De modo ainda mais crítico, Popper (1968) direciona seu olhar para o método predominantemente indutivo. No empirismo inglês esse movimento conceitual é a base para o constructo do saber. Isso porque a experiência (empiria) é a condição primeira e última para a produção do conhecimento científico. Segundo Popper (1968), o empirismo carrega a limitação de que tenta produzir verdades universais a partir de fatos concretos. O que para os empiristas é uma virtude, para Popper é a principal limitação por causa do risco do indutivismo. O autor ficou conhecido pelo célebre exemplo de que "o fato de eu ver uma garça branca não prova que todas as garças sejam brancas".

Popper sugere como solução de superação da concepção epistemológica moderna, algo que herdou do positivismo. Para ele, toda teoria ou proposição científica deveria ser testada, e não apenas testada, mas falseada. Dentro de uma perspectiva que toda afirmação científica fosse apresentada como um enunciado protocolar, ou seja, algo que precisa ser confirmado, exatamente dentro da ideia que temos na burocracia que é o protocolo. Ao protocolarmos um documento ou pedido, por exemplo, em algum órgão, significa que dependemos de uma conferência, uma comprovação, uma certificação a respeito daquele pedido ou formalização. Protocolar, porque não é a prova em si, depende de um agente externo a si, para corroborar ou não, tal solicitação. 
No caso da ciência ou da produção do conhecimento, de modo geral, Popper (1968) sugere o falseacionismo metodológico. Inicialmente, apresenta-se a inferência ou proposição científica de modo protocolar, essa precisa ser falseada, contraposta pela lógica e pela testabilidade empírica. Caso ela subsista à testabilidade, é confirmada como verdade, como ciência ou como algo universal, caso contrário é meramente pseudosaber. $\mathrm{O}$ escopo positivista está no fato de a assertiva científica não ser verdade a priori, nem mesmo por indução ou dedução, precisando ser contraposta e, resistindo aos testes, merece o status e estatuto de conhecimento. Nesse caso, a lógica, a argumentação, a retórica, não seriam aliadas e nem alinhadas com a proposição disposta, antes sim, seriam ferramentas de confrontamento lógico da proposição que se pretende universal.

Do mesmo modo, a testabilidade empírica não pretende, a priori, corroborar a hipótese, mas negá-la. As proposições que sobreviverem a esse intenso processo de contraposição merecem reconhecimento. Popper opõe-se ao modelo verificacionista. Isso porque verificar, em latim - ver se é verdade - num sentido mais amplo, parte da ideia, de certo modo viciada, de que aquela proposição é, a priori, verdadeira.

No ensino, o falseacionismo poderia produzir um efeito de libertação diante dos métodos e metodologias, tendo em vista que produzir conhecimento é, de antemão, problematizar as correntes filosóficas, as metodologias, os métodos, as teorias e os resultados produzidos pela humanidade até agora. Como se diz em Matemática, seria um tirar a prova dos 9, levar os discentes a compreender como se produziu tal saber ao tentar negá-lo. Ensinar a atitude de "falsear" teorias, leis, hipóteses, proposições, de modo geral, implica primeiro apreender como se constituiu tal saber, quais são suas bases e fundamentos, evitando que o discente seja apenas um receptor passivo de informações, quebrando os protocolos do psicologismo, do verificacionismo, do indutivismo e do dedutivismo, que são os grandes responsáveis pelo tédio e por nossas aulas enfadonhas.

Edgar Morin (2004b, 2014) nos sugere uma abordagem da ciência que parte da consciência da necessidade de uma consciência para se produzir, ensinar, fazer e difundir o conhecimento científico. Para Morin (2004a, 2004b), uma cabeça benfeita, em se tratando do discente, decorre de uma cabeça benfeita do docente e, em suma, trata-se de um olhar inter e transdisciplinar sobre o processo do conhecimento e a própria disciplina, componente curricular como tal.

Segundo Morin (1990, 2014), há necessidade de um conhecimento do conhecimento, também entendido como consciência/sabedoria. Isso, porém, só pode ser alcançado por um profundo e demorado processo de reflexão, reconhecendo primeiro que todo conhecimento é conhecimento provável, nunca absoluto. Assim, ensinar exige um movimento de reconhecimento de que todo saber produzido pelo ser humano carece de constante revisão e aprimoramento. Morin (2000) reflete que o processo de produção do conhecimento precisa considerar também o erro. O erro não revela a impossibilidade ou a inutilidade dos métodos, metodologias e formas como produzimos o conhecimento, ele apenas desvela que, também, o erro tem uma função pedagógica e epistemológica. 
Se levarmos em conta o probabilismo epistêmico de Morin (2000, 2014), nossas aulas seriam espaços de apresentação de teorias e leis, conceitos e autores, considerando todos os erros que tiveram de superar para chegar a tal resultado e, de algum modo, oportunizaria uma visão mais crítica e autocrítica sobre as soluções construídas a partir disso, tendo em vista que elas, também, carregam a potencialidade do erro. Assim, nossas aulas seriam uma convocação para a reflexão sobre como se constituiu cada tipo de conhecimento, tanto como superação de muitos erros e como a certeza na possibilidade deles, nas construções produzidas como resultado final, de suprassunção de todos os erros prováveis e possíveis, vistos e revistos até então.

A sabedoria tensionada e sugerida por Morin $(1990,2000)$ traz à tona a necessidade de que a sala de aula seja espaço para a probabilidade do erro e, ao reconhecer o erro, revisitar possíveis soluções já empreendidas, e ao mesmo tempo tencionar de modo problematizador as respostas que vão sendo elaboradas como forma de superação ou tentativa de não incorrer no erro. Morin (1990, 2000), sem dúvida, apresenta-nos uma pedagogia andante, não sedentária, assentada na necessidade de uma parceria contínua entre as diferentes formas de conhecimento, entre as diferentes áreas do conhecimento. Quanto mais as diferentes áreas do conhecimento dialogarem em torno da necessidade de juntas produzirem sentido e significado ao que está sendo ensinado, mais haverá ganho para o discente, que começará a ligar os pontos, superando o cartesianismo e (re)conectando os pontos e os saberes, (re)significando-os em direção a um ensino que não apenas transmite informações, mas oportuniza a formação e contextualização do conhecimento como empoderamento.

Lakatos (1978) e Lakatos e Musgrave (1979) também precisam ser considerados neste intento, no sentido de que se compreenda o conhecimento, e mesmo a ciência, como uma competição entre diferentes programas de pesquisa. Para eles, não é necessário que um sistema esteja imune às críticas e erros. O que precisa ser feito é que cada programa de pesquisa, em competição com outro, possibilite não a negação deste ou daquele programa de pesquisa, mas oportunize nesse tensionamento constante à solidificação do conhecimento enquanto tal.

Lakatos distancia-se de Kuhn porque para ele,

a história das ciências tem sido, e deve ser, uma história de programas de investigação competitivos (ou, se quiserem, de paradigmas), mas não tem sido, nem deve vir a ser, uma sucessão de períodos de ciência normal: quanto antes se iniciar a competição, tanto melhor para o progresso (1970, p. 59)

Embora reconheça que a tese de Kuhn seja a mais bem-aceita entre os cientistas, de modo geral, para ele, aceitar que a ciência funciona com e como paradigmas é impedir o seu verdadeiro progresso. Dando um ar mais aberto e crítico, a ciência deve evoluir num embate consistente e permanente entre teorias concorrentes. Não num sentido dialético de uma aufheben (suprassunção) de uma teoria pela outra, conforme a proposição da dialética hegeliana. Nesse caso, uma teoria ocuparia por um tempo o lugar de outra de modo que seria plena unanimidade. Para Lakatos (1978), a proliferação contínua de teorias e a competição permanente entre elas, amparadas pela heurística negativa e a positiva, vão permitindo a construção e a constituição do saber científico. 
O que precisa ser mantido é o núcleo duro e seguro da ciência, para que não tenhamos de começar sempre do zero. Assim, a heurística positiva irá corroborando e validando o conhecimento que for agregando valor de verdade ao núcleo e a heurística negativa irá refutar o que não for importante para o progresso do saber. $O$ que garante o progresso ou a degradação de uma teoria não são os desafios externos ou internos, mas o constante tensionamento com outras teorias, que ao competirem entre si podem de modo livre e contínuo oportunizar a evolução histórica da ciência. Na concepção de Lakatos (1978), uma teoria também não precisa ser falseada (como sugeriu Popper), tendo em vista que o progresso do saber não necessariamente depende da negação de uma teoria ou modelo e sua substituição por outro (LAKATOS; MUSGRAVE, 1979).

Em sala de aula repercute, à luz de Lakatos (1971a, 1978), tanto a necessidade da interdisciplinaridade quanto a abertura dos docentes e discentes a outras teorias que não apenas aquelas que estão nos livros didáticos ou ao alcance mais imediato do saber acadêmico. No caso específico, o docente deve propor uma competição simples entre as diferentes teorias e teses sobre um determinado assunto, fazendo com que os estudantes, ao se apropriarem delas, possam compreender aquilo que é um cinturão protetor da ciência, na acepção de Lakatos, e aquilo que pode e precisa ser substituído à luz da heurística positiva e negativa. A sala de aula seria como um campo de jogo, onde personagens e ideias apresentariam suas ponderações para produzir saberes aceitáveis por todos. Nesse jogo, sempre deveria ser remontada a pergunta originária e as possíveis respostas para ela e nisso docente e discentes deveriam racionalmente escolher 0 que melhor garante o progresso racional da ciência e do conhecimento. A sala de aula deve ser espaço e laboratório para a controvérsia, para a possibilidade dela, não para a disputa ou doutrinação.

Paul Feyerabend (1993), por sua vez, dedicou parte de usa obra para refletir sobre a nossa obsessão, desde René Descartes, por um método que seja seguro para nos conduzir a uma verdade clara e distinta. O racionalismo e o empirismo legaram essa busca quase que prioritária por um método para que se encontre com ele um conhecimento seguro. O próprio positivismo, mais tarde, propõe um novo método, o hipotético-dedutivo, pelo qual não se parte a priori de uma verdade, mas de hipóteses que precisam ser corroboradas, verificadas pela testagem empírica. Essa eleição de um único método é tão nociva quanto não ter método algum, segundo Feyerabend (1993).

Ao tratarmos da anarquia de método(s) não estamos propondo, à luz da visão de Feyerabend, que é possível constituirmos conhecimento sólido, válido, verdadeiro e universal abrindo mão de métodos e metodologias. O que ele sugere é que não tenhamos a mente reduzida, restrita e condicionada à utilização de um único método.

Aplicando ao contexto de sala de aula, normalmente na condição de docentes tendemos a usar como método ou metodologia de ensino, por exemplo, aquilo que experimentamos em nosso processo formativo e que deu certo, somando ao que conseguimos conceber em termos de inovação em relação àquilo que já foi produzido pela tradição e a experiência de/com nossos tutores e professores durante o nosso processo formativo. Mesmo assim, há uma resistência natural a processos que nos demovam de verdades e experiências seguras para buscar outras possibilidades de ensinar. De modo 
geral, a grande maioria dos professores assume postura conteudista, doutrinária, desconsiderando o modo como o estudante precisa aprender ou o que ele precisa lapidar de todas as pedras preciosas jogadas em seu baú mental.

Com a centralidade no professor, a tendência passa a ser a disseminação de conteúdos com carência de um olhar para a subjetividade do discente. É necessário, portanto, questionarmos nossas práticas para a valorização da autonomia do estudante, oportunizando um processo educativo que contribua para a construção de conhecimentos com sujeitos capazes de se reconhecerem no mundo e reivindicarem seus direitos.

É importante certo distanciamento ${ }^{6}$ de nossa práxis para analisarmos de modo crítico a forma que estamos ensinando e o resultado prático disso na formação do discente. Não damos aula para nosso bel-prazer ou apenas para nossa satisfação, para vencer conteúdos, estudar autores, leis, teorias, enfim, dar conta de nossas ementas nos mais diferentes componentes curriculares. A nossa satisfação, a nossa realização como docentes é algo a ser considerado também, mas a principal função nossa em sala de aula é o empoderamento dos discentes pela força teórica e prática do conhecimento produzido com nossa intervenção.

O espaço escolar é caracterizado pela conjuntura política, histórica e social em que está inserido, do mesmo modo que representa um local de múltiplas vivências e relações. Nesse contexto, mais do que conceber uma conduta ideal de estudantes e professores, deve-se propor um ambiente de reflexão e exercício do senso crítico, para que assim os sujeitos envolvidos sejam motivados ao empoderamento e tomada de consciência sobre a realidade. A prática deve ser pautada no conhecimento integrador entre sujeitos e saberes, com contínua reflexão, para que o estudante disponha de ferramentas capazes de transformar seu contexto social.

Por isso é natural, normal e desejável que busquemos sempre novas formas de abordagens, novos métodos e metodologias para dar conta de um mundo pluriversal em que vivemos. Somente a diversificação de metodologias, e de abordagens, pode garantir cumprirmos efetivamente nossa missão. A melhor qualidade de um docente é a habilidade e a competência da autodeterminação. Diante da infinidade de métodos e metodologias, não é razoável e nem produtivo escolher ou eleger sempre o mesmo modo de ensinar, como se as nossas salas de aula fossem um ambiente de culto religioso ou preleção, no qual falamos, falamos e falamos para um público desinteressado, entediado e desmotivado. Óbvio que uma aula frustrante e enfadonha não é culpa somente do professor. É verdade que uma boa aula não depende só do professor, mas também, de boas escolhas metodológicas, uma boa formação teórica e capacidade de escolher o adequado para o momento específico, recolhendo e elegendo de tudo aquilo que deve ser ensinado os elementos que são fundamentais que o discente se aproprie como condição para sua autonomia via conhecimento.

Feyerabend (1993) convida-nos à reflexão de que podemos diversificar as formas de abordagens metodológicas tanto para produzir ciência, conhecimento e inovação tecnológica, quanto para melhorar a técnica e qualificar os nossos processos de ensino

Na Fenomenologia se diz epoché, termo grego que significa suspensão, dá uma ideia de afastamento necessário para avaliarmos com clareza e criticidade uma determinada realidade ou ser. Ir às coisas mesmas. 
e aprendizagem. Isso porque, embora os conteúdos tendam a ser os mesmos por um bom tempo, ensinamos pessoas de tempos diferentes, com temporalidades, linguagens e aptidões distintas, portanto, as pessoas que acorrem até nós para aprender não são as mesmas o tempo todo.

Considerar isso não significa que a cada aula ou pesquisa tenhamos de usar métodos ou metodologias diferentes, tampouco abandonar de vez formas e métodos que dão certo. O que é mais significativo aqui é a capacidade e a liberdade do docente para constituir com seus discentes um rol de possibilidades para que se sintam estimulados e incentivados a compreender, explicar e transformar o mundo a partir da própria transformação de si pelo conhecimento produzido e oportunizado, também, em sala de aula.

\section{A HISTÓRIA DA CIÊNCIA COMO ESTRATÉGIA PARA RESSIGNIFICAR O ENSINO E A PRODUÇÃO DO CONHECIMENTO}

O objetivo central do que nos propomos aqui tem sintonia com o disposto por Bynum (2018, p. 349): “o momento de Hipócrates diferia do de Galileu ou de Lavoisier. Vestiam-se, comiam e pensavam como as outras pessoas da época (...) raciocinavam de modo mais afiado do que a maioria de seus contemporâneos (...) capazes de comunicar suas ideias". Por terem sido audaciosos do ponto de vista da curiosidade, da descoberta e da comunicação desta, serão lembrados geração após geração, por mérito.

Em sala de aula, no entanto, não significa que a prioridade seja recontar isso como uma experiência de sucesso, no sentido de ovacionar esse ou aquele inventor, essa ou aquela pessoa que contribuiu com o desenvolvimento da ciência. A ideia de contextualizar a invenção é, primeiro, para levar ao estudante que esses cientistas, pensadores e inventores; eram pessoas normais e comuns em seu tempo e sua cultura. A perspicácia, inventividade e capacidade de comunicar suas posições foram construídas e podem e precisam ser revisitadas em nosso tempo.

A história da ciência é de suma importância para levar às novas gerações todos os elementos que compuseram o cenário de tal descoberta, desmistificando e revisitando o contexto como modo de incentivar a agudez de espírito. Não se produz conhecimento sem curiosidade, sem remontar a máxima socrática de desejar saber, desejar a sabedoria. O conhecimento começa pelo desejo curioso de compreender, explicar e transformar algo. Se propusermos somente os resultados do que foi produzido em ciência, sem mesmo explicitar os erros, os contextos, as perguntas, necessidades e contingências que possibilitaram tal descoberta, empecilhos e dificuldades, nossa narrativa pode criar um distanciamento da pergunta originária e desinteresse na medida em que parece que quem fez e faz ciência é alguém dotado de um talento ou habilidade inata, sobrenatural, que não pode ser construída por todos e todas, ou pelo menos por quem se interessar em se constituir cientista.

Para Popper, citado por Morin (2014, p. 59),

a história das ciências, como a de todas as ideias humanas, é uma história de sonhos irresponsáveis, de teimosias e de erros. Porém, a ciência é uma das raras atividades humanas, talvez a única, na qual os erros são sistematicamente assinalados e, como o tempo, constantemente corrigidos. 
Alguns exemplos simples podem ajudar na explicitação da importância da contextualização histórica, onde se originou tal saber e suas demandas intelectuais mais originárias. Um célebre exemplo de que o contexto pode influenciar na formulação de uma pergunta e/ou na elaboração de uma resposta para tal indagação é Tales de Mileto. Ele formulou uma pergunta sobre a origem e o princípio que faz o mundo ser o que é e como é. A busca pela arché (arkhé, em grego, estrutura) do universo, ocupou incontáveis mentes desde os tempos mais remotos da estruturação da ciência e da tecnologia no Ocidente. Poderíamos reescrever a sua pergunta do seguinte modo: 0 que faz 0 mundo ser o que é? As tantas respostas que foram dadas a essa pergunta, seja na tentativa de respondê-la à luz de um único princípio ou da combinação de alguns elementos como o ar, a terra, o fogo e a água, como no período pré-socrático, ainda inspiram a ciência a desvendar os mistérios presentes na realidade.

A resposta de Tales de Mileto não eliminou a pergunta, o que é maravilhoso, tendo em vista que o que muda o mundo são as perguntas e não as respostas. A conclusão de Tales de Mileto sobre o princípio básico que faz o mundo ser o que é, como é, é a água. Provavelmente ele tenha respondido isso porque morava numa ilha e seu olhar alcançava o infinito e em toda a sua volta havia água. Em parte, Tales de Mileto está corretíssimo, pois a água é fundamental para a origem e manutenção da vida. Por outro, a sua pergunta é tão complexa que até hoje não conseguimos respondê-la de modo definitivo, o que é igualmente extraordinário. Atravessamos milênios, décadas e séculos e a pergunta de Tales de Mileto ainda merece nossa consideração. De onde tudo surgiu? Como surgiu? Quando surgiu a vida e como ela evoluiu? Enfim, temos um número grande de cursos superiores, com uma infinidade de pesquisadores, mesmo em nosso tempo, buscando, de algum modo, responder à pergunta de Tales.

Outro exemplo que podemos dar é Arquimedes, que desafiado pelo rei Herão, tinha de pensar um modo de resolver o desafio de saber qual era a coroa de ouro e qual era a falsa, embora externamente fossem semelhantes. O rei havia recebido uma coroa que aparentava ouro e a outra de ouro maciço. Como não podia tocar nas coroas para testá-las Arquimedes ficou numa aporia, porque não sabia como resolver o dilema. Ao entrar numa banheira para relaxar um pouco, apavorado com a demanda a ele atribuída, mergulhou o corpo na água e percebeu que ela subiu. Com isso teve uma ideia. Considerando que o ouro e os outros elementos químicos possuíssem peso diferente, refletiu que poderia mergulhar a coroa num recipiente com água e com essa experiência descobrir qual era de ouro maciço e qual era falsa, tendo em vista que a densidade do elemento faria diferença no nível da água. Ou seja, descobriu uma forma de resolver tal desafio.

Emocionado e estupefato pela própria descoberta, Arquimedes esqueceu que estava nu, saiu correndo pelas ruas dizendo, "eureca, eureca". Em grego, "eu descobri". A heurística empreendida por Arquimedes é o sonho de consumo de todo e qualquer cientista que se debruça sobre um aspecto do mistério do ser, compreender uma doença, resolver um problema de matemática, um desafio da informática, descobrir uma solução para um cálculo complexo, enfim, encontrar um modo de solucionar o problema ou pelo menos parte dele. A pergunta de Tales de Mileto e a corrida emocionada de Arquimedes pelas ruas são experiências marcantes pelo contexto, pelo enredo, pela 
narrativa e pelo simbolismo que carregam em seu sentido originário. Antes de trabalhar Tales de Mileto e Arquimedes; favorece, e muito, apresentarmos o contexto histórico e as nuances que envolveram tal descoberta. Nada é mais cativante que uma narrativa benfeita, os mitos, provam isso. Para fazer ciência, a premissa é a mesma, sem retórica e sem dialogicidade não há progresso científico.

Com Sócrates há a inversão do locus da areté (excelência), que antes estava assentado sobre a dimensão física do ser humano, por causa da física jônica, e também, porque a visão sobre o ser humano, até Homero, era de que a eternidade do homem se dava pela grandeza de suas ações. No diálogo Fédon Platão (1983) apresenta uma noção de alma imortal e que esta é a sede de uma nova excelência (areté), ou seja, a invenção conceitual de Sócrates é a de que temos uma alma e que ela deve ser o nosso maior investimento, a imortalidade do humano reside na alma e não apenas na grandeza de nossos feitos. Essa proposição socrática reinventa o foco da atenção teórica e prática do humano. Antes de Sócrates, a busca por respostas e as perguntas mais agudas eram direcionadas para explicar e compreender os mitos, os deuses e o universo. Sócrates traz à baila uma nova proposição pelo viés do autoconhecimento, tendo como foco central o próprio ser humano.

Aristóteles, que é o pai da ciência ocidental, buscou formalizar algumas definições e teses a partir da observação, da experimentação e da justificação sobre o que é conhecer, o que são e como são os seres. Obviamente que o balizador é a convicção de que somos animais racionais, animais lógicos e animais políticos. Ele buscou fundamentar sua física e astronomia em Ptolomeu, que era o conhecimento mais difundido e aceito até seu tempo, com as ferramentas conceituais que lhe estavam disponíveis e possíveis naquela época. Aristóteles (1995) no Livro IV, de sua Física, defendeu a eternidade do mundo. Em sua Metafísica, Aristóteles (1969) propõe a noção de sinolo, como junção da matéria e forma. Conceitualmente isso une e responde aos desafios teóricos propostos por Heráclito (devir) e Parmênides (ser), apresentando uma noção de ato (ser) e potência (devir), e de essência (ousia). A proposta filosófica e científica de Aristóteles perpassou os séculos, constituindo até hoje referência e problema teórico para os embates e debates científicos e filosóficos.

Roger Bacon retoma a visão aristotélica e abre perspectivas para o que mais tarde denominamos como cerne do pensamento moderno, a ciência experimental. Comumente, atribuímos esse feito a Galileu Galilei e a Nicolau Copérnico, mas os estudos do monge franciscano sobre o arco-íris, reflexão e refração da luz foram fundamentais para a invenção das lentes ópticas e, posteriormente, os telescópios, óculos, etc. Além de seus estudos com óptica, descobriu a pólvora de propulsão, deixando-nos como legado a ciência experimental. Sua paixão por astronomia, matemática e pelas ciências experimentais custaram-Ihe a reclusão, sem fazê-lo perder o entusiasmo e curiosidade para investir em suas descobertas científicas. Bacon foi condenado pela igreja e por sua Ordem Franciscana por sua inventividade e ousadia, e seu legado foi a ciência experimental.

Um século e meio mais tarde, o também religioso Nicolau Copérnico e o filósofo Galileu Galilei foram aos poucos confrontando as verdades aristotélicas sobre astronomia, ciências em geral, e com recursos provenientes das invenções de Roger Bacon, no 
caso a invenção da lente, contestaram, entre outras coisas, a teoria do geocentrismo de Ptolomeu, assumida por Aristóteles. E, de algum modo, geraram atrito com a Igreja porque suas convicções a respeito do heliocentrismo colocaram em questão algumas passagens bíblicas que davam a entender que era o Sol que girava em torno da Terra, como na passagem bíblica da guerra contra os filisteus, em que Josué levantava a mão e o Sol parava, entre outras.

Notemos aqui que não foi um embate de religião contra ciência apenas, como comumente se defende. Foi um embate entre a Física e a Astronomia aristotélica e a visão heliocêntrica de universo, que mais tarde, diga-se de passagem, também é colocada em xeque por Giordano Bruno, ao afirmar que o universo era infinito, portanto não faria sentido defender que o Sol ou a Terra fossem o centro.

Leonardo da Vinci foi o grande destaque da virada de 1500, com seus estudos sobre náutica e aeronáutica, aliado ao fato de que propôs uma visão interdisciplinar entre Arte e Engenharia, fazendo com que suas prospecções e projeções representassem um verdadeiro salto em termos científicos, técnicos e tecnológicos. Os achados de Galileu Galilei (1988) representaram um avanço enorme, ao estudar e explicar a resistência dos materiais. Outro autor que merece destaque é Gilbert (1958), com a obra que definiu em primeira mão o que é eletricidade. Thomas Savery, ao projetar o motor a vapor, em 1698 , abriu portas para uma nova visão sobre o mundo e sobre a relação do homem com o espaço e o tempo.

O que há de novo nesses autores é a articulação entre o saber dedutivo da Física e a sua implicação prática, desde a compreensão da estrutura dos materiais até a aplicação desses conceitos e conhecimentos à Engenharia Náutica e, em nosso tempo, Aeronáutica. Quando a Igreja interpelou Copérnico e Galileu, bem como quando queimou Giordano Bruno, em 1600, não tinha clareza do erro que estava cometendo, pois acreditava que a ciência poderia afastar o homem de Deus e da verdade. Quando Roger Bacon responde ao Papa Clemente VI que o problema do mundo não é a ciência, mas a ignorância, está inaugurando um novo tempo, em que a razão humana é convocada para solucionar os grandes desafios da existência do homem. Francis Bacon, com seu Novum Organum, sacramenta essa compreensão de que saber é uma forma de poder sobre o mundo. Se no período mítico o homem temia a natureza e no período medieval a considerava sagrada, criação divina, com Bacon e Descartes a humanidade passou a vê-la como uma bruxa, a ser subjugada, realidade a ser dominada e controlada.

Augusto Comte (1978) traz à tona uma nova teoria, que é a dos três estados, com os dois primeiros, religioso e filosófico, sendo colocados em oposição em relação ao último estado, que é o científico. Este último evoluiu como uma suprassunção dos dois anteriores, entendendo-se aqui o método proposto por ele, da hipótese mais a verificação com a base empírica, dentro de sua visão restritiva a respeito de uma possível hierarquia dos saberes.

Para Comte, a Matemática, a Biologia, a Física e a Química, por exemplo, estariam num nível mais elevado por possuírem possibilidade de "positus", isto está posto, em latim, basicamente a possibilidade de uma mensurabilidade. Embora fundamental para o desenvolvimento científico no Ocidente, a tese central de Augusto Comte é autorrefutante. Isso porque ele afirmava que só tinha valor de verdade o que pudesse ser quan- 
tificado, medido e pesado, no entanto não há como aplicar a própria exigência lógica empreendida ao contexto de sua proposição. Não há como medir, pesar ou quantificar o valor de sua afirmação. Nisso, portanto, notamos fragilidade e inconsistência teórica, até porque toda noção de objetividade é, na verdade, resultado da subjetividade humana, mesmo no caso da Matemática e da Física, por exemplo.

Retomando o mote desta reflexão, notamos que na história da ciência não há uma história de teorias sucessivas, como nos lembra Lakatos (1978). Para ele, o que move a História em termos de conhecimento científico é a oposição entre tendências ou teorias concorrentes, mas nunca a supremacia plena de uma que substitui todas as outras. Há um tensionamento constante entre várias teorias, mas nunca a superação plena e absoluta de todas por uma estabelecendo um paradigma, como propôs Thomas Kuhn (1978).

Nenhuma teoria da racionalidade resolverá jamais problemas como o do porquê a genética mendeliana desapareceu da Rússia Soviética nos anos 50 , ou porque certas escolas de investigação em diferenças genéticas raciais ou na economia de ajuda externa caíram em descrédito nos países anglo-saxões nos anos 60 . Além disso, para explicar os diferentes ritmos de desenvolvimento dos diferentes programas de investigação podemos ter necessidade de invocar a história externa. A reconstrução racional da ciência (no sentido em que uso o termo) não pode abranger tudo porque os seres humanos não são animais completamente racionais; e mesmo quando agem racionalmente, podem ter uma falsa teoria de suas próprias ações racionais (LAKATOS, 1971a, p. 114).

Ao trazermos ao texto a hegemonia de correntes filosóficas como o empirismo, o racionalismo, o positivismo, entre outras, tanto numa interpretação retroativa da história do pensamento humano como numa prospecção de futuro da humanidade, como se fossem paradigmas dominantes, servem mais para reflexão do que como modelos predominantes de pensamento. Não significa reconhecer que durante tal período histórico todas as pessoas pensassem de modo uniforme. Cabe a visão de Kuhn (1978), num sentido de paradigma (algo provisório), mas é necessária a visão de Lakatos para reconhecermos que sempre houve teorias em conflito, programas de pesquisa com outras perspectivas de pensamento, e que em nosso tempo isso é imensamente salutar, porque mantém viva a capacidade do ser humano construir e reconstruir a ciência e o pensamento universal como algo vivo, evolutivo e produto da ação e concepção humana.

Como afirma Vargas (1992, p. 103), “O mundo não é um objeto. Nós estamos sempre nele, mas ele não é nunca um objeto para nós [...] O mundo não se fecha, não se explica por si mesmo". Dessa forma, como estamos e somos parte do mundo toda a transformação, de maneira direta ou indireta, reflete em nós, afinal. Assim sendo, parece ser necessária uma visão global que permita o entendimento de que a ciência compreende verdades óbvias, mas não absolutas, portanto passíveis de transformações e modificações ao longo do tempo.

A ideia de que a ciência se desenvolveu na História de modo neutro e isento já foi amplamente problematizada por Japiassu (1975) e, recentemente, por Harari (2016), que, como historiador, traz uma gama de fatos e elementos para inferir que a ciência muito se guia e já se guiou por ideologias de cunho político, religioso e econômico. 
Exemplos não faltam no livro para comprovar que a ciência depende da decisão humana, e que nem sempre essa escolha condiz com o bem comum. Isso não a inviabiliza e nem a invalida, precisamos reconhecer na esteira do que Bynum (2018) infere que a ciência atual é a mais poderosa de todos os tempos.

Tem-se isso bastante presente no campo da genética, visto que o conhecimento do genoma humano e a aplicação de novas técnicas, incluindo células-tronco, reprodução assistida, diagnósticos pré-implantação, entre tantas outras, trazem à tona novas maneiras de encarar a vida e, consequentemente, decisões que extrapolam o simples objetivo biológico. Como bem nos lembra Zatz (2011), aquilo que para a ciência genômica parece, numa concepção primária, carregada de certezas e determinismos, coloca o homem a resolver questões de ordem ética para as quais não temos as repostas definidas e, tampouco, fazemos as perguntas necessárias. Essa é a nova forma como a ciência e as técnicas influenciam o ser e estar do homem no mundo.

É nesse momento que o ensino de Biologia, por uma perspectiva integrada, coloca o aluno a pensar a ciência considerando o impacto que ela tem na compreensão da realidade e na determinação de escolhas que garantam a dignidade e qualidade de vida humana.

A relação estreita entre ciência, técnica e tecnologia permite-nos chegar a lugares e espaços jamais imaginados. Como Bynum afirma, "a ciência e a tecnologia podem ser utilizadas com fim escusos com a mesma facilidade com que podem ser aplicadas ao bem comum" (2018, p. 340). Por isso, não basta compreendermos e ensinarmos as teorias científicas, "precisamos de bons cientistas, mas também de bons cidadãos que assegurem que a nossa ciência torne o mundo um lugar melhor para todos" (BYNUM, 2018, p. 340).

\section{CONSIDERAÇÕES FINAIS}

A ciência é uma fabricação humana, constructo humano, portanto não está isenta de erros (MORIN, 2000, 2014), não está livre de ser guiada por ideologias (HARARI, 2016), de estar subordinada a interesses econômicos que podem encolher a liberdade e a autonomia das pessoas (FUKUYAMA, 2002). Isso significa que devemos considerar a ciência dentro da perspectiva que ela deva ser avaliada, considerada; e refletida à luz dos seus pares (FUKUYAMA, 2002), sem substituí-la por obscurantismos ou negá-la integralmente. As limitações da ciência requerem um posicionamento alinhado ao que Bynum (2018); Nussbaum (2010) e Morin (2014) defendem, que antes de formar cientistas, devemos formar "bons" seres humanos, voltados para a cidadania e o bem comum, considerando o fato de que sob nenhum aspecto a ciência é neutra (JAPIASSU, 1975, 1986).

Para Morin (2014), tanto as ciências humanas quanto as ciências da natureza precisam considerar pelo viés epistemológico e ético, que tão importante quanto a produção do conhecimento é o exercício do conhecimento do conhecimento - a sabedoria. Exatamente isso, considerando que esse resultado é sinônimo de sabedoria. Pensar a ciência como produto humano, como fabricação humana (CHALMERS, 1993, 1994) é reconhecer toda sua potencialidade e também seus limites. 
Compreendermos a ciência como processo humano, importante, insubstituível, não só pelo lucro imediato e crescimento das riquezas nas últimas décadas, como também pelo bem-estar e o conforto humano. São tantas melhoras, seja a produção de bens e serviços, como em melhores resultados com menor esforço, no entanto não podemos esquecer que ela como resultado de nossas escolhas e intenções também pode trazer novos desafios, a ciência não é neutra e tampouco os cientistas o são (FUKUYAMA, 2002).

A ciência é um patrimônio da humanidade que precisa receber maior atenção em todos os sentidos. É de suma importância que as novas gerações tenham um encantamento mínimo pela ciência para que possamos garantir o seu desenvolvimento, seu progresso e sua consolidação, bem como a necessária vigilância, como alertou Kant (2013), visando a garantir que o ser humano seja sempre fim, não meio. Em nome da ciência já se fez, e ainda se pode fazer, uso para "fins escusos" (BYNUM, 2018), portanto essa vigilância em torno dela nunca é para impedi-la de ser e existir, mas para que cumpra sua natureza e papel de preocupação e serviço ao bem comum.

A filosofia da ciência pode refazer a pergunta metafísica do que é a ciência, de como ela se constitui, de suas bases epistemológicas, de suas potencialidades e limitações, de como progride, etc. A filosofia da ciência é uma lente intelectual para olhar a ciência como objeto de reflexão, para pensar a sua identidade e natureza, bem como de seu papel insubstituível na vida humana. Desse modo, o docente deve fazer o exercício da reflexão sobre ciência e problematizar os seus métodos e metodologias, os paradigmas em que se assenta a ciência, as ideologias que rondam seus fazeres e achados, tendo em vista que estes precisam ser depurados, refinados, transcendidos para que a ciência possa cumprir sua finalidade.

O olhar filosófico sobre a ciência remonta sua condição primeira de (re)fazer as perguntas que nos movem para a busca do conhecimento. A ciência, em qualquer tempo, não deixa de ser o movimento de Tales de Mileto da busca dos princípios mais basilares que fundam a realidade; também não deixa de ser conexão com a proposição socrática (PLATÃO, 1972), não como um determinismo da ignorância, mas como primeiro passo para desejar e buscar o conhecimento, a sabedoria.

A história da ciência tem um papel insubstituível na formação de quem for lidar com o ensino, porque desmistifica a ideia de que quem faz ciência é alguém com dons ou poderes sobrenaturais. Antes, sim, a ciência é tentativa e erro. Deve ser uma motivação para a curiosidade. Ensinar ciência é, primeiro, ensinar uma cosmologia (COLLINGWOOD, 1986), pois ensinamos a partir de uma ideia de natureza e o entendimento que temos sobre o que ela é e como se constitui o mundo natural sempre é a condição para se fazer ciência e, sem dúvida nenhuma, é condição primeira para todo e qualquer ensino. Burguete (2004) também corrobora essa visão, partindo da premissa de que ensinamos e compreendemos o mundo a partir de um modelo conceitual dado e, portanto, fazemos e ensinamos ciência dentro de um modelo, dentro de uma visão de mundo, que não deixa de ser uma visão da natureza (COLLINGWOOD, 1986). 


\section{REFERÊNCIAS}

ARISTÓTELES. Metafísica. Tradução Leonel Vallandro. Prefácio David Ross. Porto Alegre: Globo, 1969. ARISTÓTELES. Física. Tradução espanhola G. R. de Echandria. [S.I.]: Editorial Gredos, 1995.

ARISTÓTELES. Nicomachean Ethics. London: Loeb Classical Library, 1990.

BACHELARD, G. O novo espírito científico: contribuição para uma psicanálise do conhecimento. Tradução Estrela dos Santos Abreu. Rio de Janeiro: Contraponto, 1996.

BACHELARD, G. A epistemologia. Tradução Fátima Lourenço Godinho e Mário Carmino Oliveira. Lisboa, Portugal: Edições 70, 2006.

BURGUETE, M.C. História e filosofia das ciências. Lisboa: Instituto Piaget, 2004.

BYNUM, W. Uma breve história da ciência. Tradução luri Abreu. Porto Alegre: L\&PM, 2018.

CARROLL, L. Alice au pays des merveilles suivi de La traversée du miroir. Paris: Le Livre de Poche. 2009.

CHALMERS, A. F. O que é ciência, afinal? São Paulo: Brasiliense, 1993.

CHALMERS, A. F. A fabricação da ciência. São Paulo: Unesp, 1994.

COLLINGWOOD, R. G. Ciência e filosofia: a idéia de natureza. 5. ed. Lisboa: Editorial Presença, 1986.

COMTE, A. Curso de filosofia positiva; discurso sobre o espírito positivo; discurso preliminar sobre o conjunto do positivismo; catecismo positivista. Tradução José Arthur Giannotti e Miguel Lemos. São Paulo: Abril Cultural, 1978.

DESCARTES, R. Discurso do Método. Tradução Maria Ermantina Galvão. São Paulo: Martins Fontes, 1996. EINSTEIN, A. Como vejo o mundo. Tradução H. P. de Andrade. Rio de Janeiro: Nova Fronteira, 1981.

FAZENDA, I. (org.). Práticas interdisciplinares na escola. 6. ed. São Paulo: Cortez, 1999.

FEYERABEND. P. K. Against method. London: Verso, 1993.

FRIGOTTO, G.; CIAVATTA, M.; RAMOS, M. (org.). Ensino Médio integrado: concepção e contradições. São Paulo: Cortez, 2005.

FUKUYAMA, F. Our posthuman future: consequences of the biotechnology revolution. New York: Farrar, Straus and Giroux, 2002.

GALILEI, G. Duas novas ciências. 2. ed. São Paulo: Editora Stella, 1988.

GILBERT, W. On the Magnet. Trad. Inglesa de S. P. Thompson. Nova York: Basic Books, 1958.

HARARI, Y. N. Sapiens: uma breve história da humanidade. 11. ed. Porto Alegre: L\&PM, 2016.

JAPIASSU, H. O mito da neutralidade científica. Rio de Janeiro: Imago, 1975.

JAPIASSU, H. Introdução ao pensamento epistemológico. 4. ed. Rio de Janeiro: Francisco Alves Editora, 1986.

KANT, I. A metafísica dos costumes. São Paulo: Editora Universitária São Francisco, 2013.

KUHN, T. S. A estrutura das revoluções científicas. 2. ed. São Paulo: Perspectiva, 1978.

LAKATOS, I. Falsification and the methodology of scientific Research Programmes. In: The methodology of scientific research programmes Philosophical Papers, v. I. Edited by John Worrall and Gregory Currie. New York, Cambridge: Cambridge University Press, 1978.

LAKATOS, I. History of Science and its Rational Reconstruction. Boston Studies in the Philosophy of Science, v. 8, 1971a.

LAKATOS, I. Reply to Critics. In: BUCK, R. C.; COHEN, R. S. (ed.). Memory of Rudolph Carnap. Boston Studies in the Philosophy of Science, Dordrecht: Reidel, 1971b. V. 8.

LAKATOS, I. The methodology of scientific research Programmes. Philosophical Papers. Cambridge: Cambridge University, 1978. V. 1.

LAKATOS, I.; MUSGRAVE, A. A crítica e o desenvolvimento do conhecimento. São Paulo: Cultrix, 1979.

MORIN, E. Introdução ao pensamento complexo. Lisboa: Instituto Piaget,1990.

MORIN, E. Os setes saberes necessários à educação do futuro. Tradução Catarina Eleonora F. Silva e Jeanne Sawaya. São Paulo: Cortez, 2000.

MORIN, E. A religação dos saberes: o desafio do século XXI. Rio de es Janeiro: Bertrand Brasil, 2004a.

MORIN, E. A cabeça bem-feita: repensar a reforma, reformar o pensamento. Rio de Janeiro, Bertrand Brasil, 2004b.

MORIN, E. Ciência com consciência. Rio Janeiro: Bertrand Brasil, 2014.

NUSSBAUM, M. Not for profit. Why democracy needs the Humanities. Princeton: Princeton University Press, 2010.

PLATÃO. Defesa de Sócrates. Tradução Jaime Bruna. São Paulo: Abril, 1972. 
PLATÃO. Fédon. Tradução Jorge Paleikat e João Cruz Costa. São Paulo: Abril Cultural, 1983 (Coleção Os Pensadores).

PLATÃO. As Leis. São Paulo: Edipro, 1999.

POPPER, K. The logic of scientific discovery. New York: Harper, 1968.

SANTOMÉ, J. Globalização e interdisciplinaridade: o currículo integrado. Porto Alegre: Artes Médicas, 1998.

SANTOS, B. de S. Um discurso sobre as ciências. 16. ed. Porto: B. Sousa Santos; Edições Afrontamento, 2010.

VARGAS, M. Ciência, técnica e realidade. Revista USP, n. 14, p. 96-103, São Paulo, 1992. Disponível em: http://www.revistas.usp.br/revusp/article/view/25652/27389. Acesso em: 3 maio 2020.

ZATZ, M. Genética: a escolha que nossos avós não faziam. 1. ed. São Paulo: Globo, 2011. 